\title{
Prediction of Solidification Microstructure and Columnar-to- equiaxed Transition of Al-Si Alloy by Two-dimensional Cellular Automaton with “Decentred Square” Growth Algorithm
}

\author{
Hongwei ZHANG, ${ }^{1)}$ Keiji NAKAJIMA, ${ }^{2)}$ Rangqiong WU, ${ }^{1)}$ Qiang WANG ${ }^{1)}$ and Jicheng HE ${ }^{1)}$ \\ 1) Key Laboratory of Electromagnetic Processing of Materials, Ministry of Education, Northeastern University, Wenhua Road \\ 3-11, Shenyang, 110004, China. E-mail: hongweizhang@epm.neu.edu.cn \\ 2) Division of Applied Process Metallurgy, \\ Department of Materials Science and Engineering, Royal Institute of Technology (KTH), SE-100 44 Stockholm, Sweden.
}

(Received on December 26, 2008; accepted on March 13, 2009)

\begin{abstract}
A Cellular Automaton (CA) -Finite Difference (FD) coupling model was developed to analyze the evolution of solidification microstructure and the columnar-to-equiaxed transition (CET) in Al-Si alloy. Kobayashi's microsegregation equation was adopted to describe the solute diffusion in solid phase, and a "decentred square" growth algorithm with coordinate transformation was performed to describe the grain growth and the entrapment of neighbor cells. Through the examination on the effects of operation parameters and nucleation parameters on solidification morphologies, it was found that the length of columnar grains is controlled by the dendrite tip growth kinetics, and that the width of columnar grains is controlled by the implicit relationship between nucleation density and cooling rate at ingot surface. It was also found that the size of equiaxed grains is controlled by the competition of the nucleation and the grain growth. With the controllability of nucleation density in the bulk of liquid for equiaxed grain size, the nucleant and the nucleation density in actual Al-Si alloy were estimated. Both of the CET criteria based on the solidification path by CA-FD coupling model and the one based on the curves of critical temperature gradient conditions by Hunt's model were strongly dependent on nucleation undercooling and Si concentration. A good agreement was obtained between these two.
\end{abstract}

KEY WORDS: Al-Si alloy; solidification microstructure; grain size; nucleant; CET; Cellular Automaton.

\section{Introduction}

Cellular Automaton (CA) models have been developed for the prediction of dendritic grain structures formed in solidification processes. Rappaz and Gandin ${ }^{1)}$ have firstly proposed the CA model for the prediction of solidification microstructure in uniform temperature field. Its main idea was to track the positions of growth fronts of the dendritic grains, however, the internal structure of the dendritic grains was not modeled. In other words, only the development of grain envelopes was taken into account by using the dendrite tip growth kinetics related to the local undercooling. Since then, the model has been developed to predict the solidification microstructure not only in uniform temperature field but also in gradient temperature field, 2,3 ) from two dimensional configuration to three dimensional one. A fully coupling between finite element (FE) method and cellular automaton model $(\mathrm{CA})^{4)}$ was realized at last. Recent CA models also considered the effects of fluid flow and macrosegregation. ${ }^{5)}$

To meet the demands of industrial applications, CA model is usually coupled with finite difference (FD) or finite element (FE) method. At the macroscopic scale, the temperature field is resolved by using FD or FE method. Thus the local undercooling obtained in FD mesh nodes is related to the nucleation and the dendrite tip growth kinetics in CA cells at microscopic scale. Cho et al. ${ }^{6)}$ have coupled FD with CA model in order to predict the solidification microstructure of Al-Si alloy and examined the effects of nucleation parameters. Scheil's equation for microsegregation was combined with heat transfer procedure in their model. Nakajima and Mizoguchi, ${ }^{7)}$ adopting Kobayashi's equation for microsegregation ${ }^{8)}$ which considers the solute diffusion in solid phase, predicted the temperature field and the solidification process for multi-component alloy.

In the present work, a CA-FD coupling model is developed to analyze the effects of operation parameters and nucleation parameters on the development of solidification microstructure in Al-Si alloy. The microsegregation combined with heat transfer procedure in FD method is described by Kobayashi's equation, and the grain growth procedure in CA model is described by two dimensional (2D) "decentred square" growth algorithm. ${ }^{3)}$ The effects of operation parameters and nucleation parameters on the solidification microstructure, especially on the size of columnar and equiaxed grains, are discussed by comparing predicted results with previous experimental ones. Identification of nucleant and estimation of its nucleation density in actual Al-Si alloy is done using the CA-FD coupling model. In addition, the critical conditions for columnar-to-equiaxed 
transition (CET) are predicted from the development of solidification microstructure using the CA-FD coupling model, and are compared with those from the models of Hunt and Stefanescu.

\section{CA-FD Coupling Model}

An unsteady two dimensional heat transfer procedure combined with solute redistribution at solid/liquid (S/L) interface during solidification is considered in Al-Si alloy ingot. The accurate temperature field is obtained following the energy balance. The temperature is then interpolated into CA cells and related to the nucleation procedure and the grain growth procedure.

\subsection{FD Method for Temperature Field}

The heat transfer equation combined with microsegregation model ${ }^{7,8)}$ is adopted to obtain the temperature field. The unsteady heat transfer equation is expressed as

$$
\frac{\partial H}{\partial t}=\nabla \cdot(\kappa \nabla T)
$$

It is rewritten by the explicit difference scheme as

$$
H_{n+1}=H_{n}+\nabla \cdot\left(\kappa \nabla T_{n}\right) \Delta t
$$

where $H_{n+1}$ is the enthalpy per unit volume at $n+1$-th time step, $\kappa$ is the thermal conductivity, $T_{n}$ is the temperature at $n$-th time step, $\Delta t$ is the time step in FD method which is determined by stability analysis of explicit difference scheme. The boundary condition adopted at ingot surface is

$$
-\kappa \frac{\partial T}{\partial n}=h\left(T-T_{\infty}\right)
$$

where $n$ is the normal to ingot surface, $h$ is the heat transfer coefficient, $T_{\infty}$ is the surrounding temperature.

The energy balance among enthalpy, $H$, solid fraction, $f_{S}$, and temperature, $T$, is expressed in Eq. (4). Assuming the molten alloy being a dilute solution and the local equilibrium at solid/liquid $(\mathrm{S} / \mathrm{L})$ interface, temperature, $T_{n+1}$, is obtained through Eq. (5). The microsegregation model adopted is Kobayashi's solution of Brody-Fleming's solidification model, which considers solute diffusion in solid phase. ${ }^{8)}$ Here solute concentration in liquid, $C_{n+1}$, is expressed as a function of solid fraction, $f_{S, n+1}$, as shown in Eq. (6).

$$
\begin{array}{r}
H_{n+1}=\rho \Delta H_{L S}\left(1-f_{S, n+1}\right)+\rho C_{p} T_{n+1} \ldots \ldots \ldots \ldots . . . . \\
\frac{1}{T_{n+1}}=\frac{1}{T_{L}^{0}}+\frac{R}{\Delta H_{L S}}\left(1-k^{S / L}\right) \frac{C_{n+1}}{W} \ldots \ldots \ldots . . . \\
C_{n+1}=C_{n}\left(\frac{P_{n+1}}{P_{n}}\right)^{\zeta}\left[1+\frac{k^{S / L}\left(1-k^{S / L}\right) \beta^{3}}{2 \gamma\left(1-\beta k^{S / L}\right)^{3}}\left(Q_{n+1}-Q_{n}\right)\right]
\end{array}
$$

where $\rho$ is the density, $C_{p}$ is the specific heat. $T_{L}^{0}$ is the melting point of pure metal, $\Delta H_{L S}$ is the latent heat of solidification as a function of solute concentration. $C^{0}$ and $W$ are the atomic weight of solute element. $k^{S / L}$ is the equilibrium partition coefficient. The terms of $P_{n}, Q_{n}, \beta, \gamma$ and $\zeta$ are expressed as functions of solid fraction, $f_{S, n}$, secondary arm spacing, $\lambda_{2}$, and diffusion coefficient in solid phase, $D_{S}{ }^{8)}$

Given the initial conditions of solute concentration, $C^{0}$, superheat, $\Delta T_{\text {superheat }}$, and external cooling condition (heat transfer coefficient, $h$ ), temperature, $T_{n+1}$, solid fraction, $f_{S, n+1}$, and solute concentration, $C_{n+1}$, can be determined simultaneously by iterative solution of Eqs. (2), (4), (5) and (6).

Once the concentration reaches the eutectic point, the temperature and the concentration are maintained until the solid fraction reaches unity. Afterwards, they change again with solidification progress.

\subsection{CA Model for Solidification Microstructure in Gradient Temperature Field}

The final solidification microstructure observed in cross section of an ingot can be characterized by three main phenomena: local undercooling, nucleation of grains and its preferential growth orientation. The CA model including the nucleation procedure and the grain growth procedure is adopted to predict the development of solidification microstructure in a gradient temperature field.

\subsubsection{Local Undercooling}

The temperatures in FD mesh nodes are interpolated into CA cells linearly firstly in time and then in space, because both time step and cell size in CA procedure are smaller than those in FD procedure.

The micro time step, $\delta t$, is determined to limit the interface moving within one cell in one time step,

$$
\delta t=\min \left[\frac{l_{C A}}{v_{\text {tip }}\left(\Delta T_{\text {max }}\right)}, \Delta t\right]
$$

where $l_{C A}$ is CA cell size, $v_{\text {tip }}\left(\Delta T_{\max }\right)$ and $\Delta T_{\max }$ are the maximum growth rate of dendrite tip and the maximum local undercooling among all growing cells found in the calculation region, respectively.

The CA cell size is set as $1 / 4$ or $1 / 5$ length of primary arm spacing, $\lambda_{1}$, which is determined from the cooling rate at ingot surface, $\dot{T}_{\text {surface }}$ (in Table $\mathbf{1}$ ).

Firstly the temperature of a FD mesh node at CA time, $t+\delta t$, is obtained by linear interpolation of the corresponding values at time, $t$ and $t+\Delta t$. Then the temperature of a CA cell is obtained by double linear interpolation of the corresponding values at four nearest FD mesh nodes.

Once the temperature at $\mathrm{CA}$ cell is lower than liquidus temperature, it is undercooled and becomes the potential cell for the nucleation and the grain growth.

\subsubsection{Nucleation}

Both locations and crystallographic orientations for new nucleus are chosen randomly. The continuous nucleation distribution, $d n_{V} / d\left(\Delta T_{V}{ }^{\prime}\right)$, is described by Gaussian distribution (Eq. (8)). When the nucleation probability of a CA cell, $P_{V}=\delta n_{V} \cdot V_{C A}$, is greater than a random number, $r$ $(0 \leq r \leq 1)$, during a micro time step, $\delta t$, the cell is nucleated. Its state is changed from liquid to solid, and it is given a random crystallographic orientation, $\theta$, which is the angle 
Table 1. Thermophysical properties of Al-Si alloys used in the CA-FD coupling model.

\begin{tabular}{|c|c|c|c|c|c|}
\hline Parameter & Symbol & Unit & $\mathrm{Al}-3 \mathrm{mass} \% \mathrm{Si}$ & $\mathrm{Al}-5 \mathrm{mass} \% \mathrm{Si}$ & $\mathrm{Al}-7 \mathrm{mass} \% \mathrm{Si}$ \\
\hline $\begin{array}{l}\text { Initial solute concen- } \\
\text { tration in liquid }\end{array}$ & $C^{0}$ & - & 0.03 & 0.05 & 0.07 \\
\hline Melting point of pure $\mathrm{Al}$ & $T_{L}^{0}$ & ${ }^{0} \mathrm{C}$ & & $660.35^{9)}$ & \\
\hline Liquidus temperature & $T_{L}$ & ${ }^{0} \mathrm{C}$ & 642.816 & $632^{11)}$ & $618^{9)}$ \\
\hline Initial temperature & $T_{i n i}$ & ${ }^{0} \mathrm{C}$ & \multicolumn{3}{|c|}{800} \\
\hline Primary arm spacing & $\lambda_{1}$ & $\mathrm{~m}$ & \multicolumn{3}{|c|}{$220 \times 10^{-6} \times\left(\dot{T}_{\text {Surface }}\right)^{-0.5511)}$} \\
\hline Secondary arm spacing & $\lambda_{2}$ & $\mathrm{~m}$ & \multicolumn{3}{|c|}{$5 \times\left(M \cdot t_{S L}\right)^{1 / 311)}$} \\
\hline $\begin{array}{l}\text { Coefficient in the } \\
\text { expression of } \lambda_{2}\end{array}$ & M & $\mathrm{m}^{3} / \mathrm{s}$ & $\left.7.73 \times 10^{-18} 11\right)$ & $6.30 \times 10^{-18}$ & $5.43 \times 10^{-18}$ \\
\hline Solidification time & $t_{S L}$ & s & \multicolumn{3}{|c|}{ (local time -solidification beginning time) } \\
\hline $\begin{array}{l}\text { Diffusion coefficient of } \\
\text { Si in solid phase }\end{array}$ & $D_{S}$ & $\mathrm{~m}^{2} / \mathrm{s}$ & \multicolumn{3}{|c|}{$D_{S}=D_{0} \cdot \exp (-Q / R T), T,[K]{ }^{12)}$} \\
\hline $\begin{array}{l}\text { Diffusion constant in the } \\
\text { expression of } D_{S}\end{array}$ & $D_{0}$ & $\mathrm{~m}^{2} / \mathrm{s}$ & \multicolumn{3}{|c|}{$\left.2.0 \times 10^{-4} \quad 12\right)$} \\
\hline Activity energy & $Q$ & $\mathrm{~J} / \mathrm{mol}$ & \multicolumn{3}{|c|}{$\left.1.335 \times 10^{5} 12\right)$} \\
\hline Specific heat & $C_{p}$ & $\mathrm{~J} / \mathrm{m}^{3} \mathrm{~K}$ & \multicolumn{3}{|c|}{$\left.2.6 \times 10^{6} 13\right)$} \\
\hline Thermal conductivity & $\kappa$ & $\mathrm{W} / \mathrm{m} \mathrm{K}$ & \multicolumn{3}{|c|}{$\kappa=\kappa_{S} \cdot f_{S}+\kappa_{L} \cdot f_{L}$} \\
\hline $\begin{array}{l}\text { Thermal conductivity in } \\
\text { liquid }\end{array}$ & $\kappa_{L}$ & $\mathrm{~W} / \mathrm{m} \mathrm{K}$ & $\begin{array}{c}\kappa_{L}=41.5+0.0312 T \\
T,[K]{ }^{14)}\end{array}$ & $90^{11)}$ & $\begin{array}{c}\kappa_{L}=365+0.028 T \\
T,[K]^{14)}\end{array}$ \\
\hline $\begin{array}{l}\text { Thermal conductivity in } \\
\text { solid }\end{array}$ & $\kappa_{S}$ & $\mathrm{~W} / \mathrm{m} \mathrm{K}$ & $\begin{array}{c}\mathrm{\kappa}_{S}=253-0.110 T \\
T,[K]{ }^{14)}\end{array}$ & $104^{11)}$ & $\begin{array}{c}\kappa_{S}=233-0.110 T \\
T,[K]{ }^{14)}\end{array}$ \\
\hline Density & $\rho$ & $\mathrm{kg} / \mathrm{m}^{3}$ & \multicolumn{3}{|c|}{$2452.5^{9)}$} \\
\hline Partition coefficient & $k^{S / L}$ & - & \multicolumn{3}{|c|}{$k^{S / L}=0.1125+0.25 \times C_{S i}$} \\
\hline $\begin{array}{l}\text { Latent heat of } \\
\text { solidification }\end{array}$ & $\Delta H_{L S}$ & $\mathrm{~kJ} / \mathrm{kg}$ & \multicolumn{3}{|c|}{$397.0-473.68 C_{S i}-2004.5 C_{S i}^{2}$} \\
\hline $\begin{array}{l}\text { Gibbs-Thomson } \\
\text { coefficient }\end{array}$ & $\Gamma$ & $\mathrm{K} \mathrm{m}$ & $\left.1.96 \times 10^{-7} 14\right)$ & $1.96 \times 10^{-7}$ & $\left.1.96 \times 10^{-7} 14\right)$ \\
\hline Slope of liquidus & $\mathrm{m}$ & $\mathrm{K} /-$ & $-600 .{ }^{14)}$ & -625 & $-650 .{ }^{14)}$ \\
\hline $\begin{array}{l}\text { Diffusion coefficient of } \\
\text { Si in liquid phase }\end{array}$ & $D_{L}$ & $\mathrm{~m}^{2} / \mathrm{s}$ & $\left.7.0 \times 10^{-9} 14\right)$ & $6.725 \times 10^{-9}$ & $\left.6.45 \times 10^{-9} 14\right)$ \\
\hline
\end{tabular}

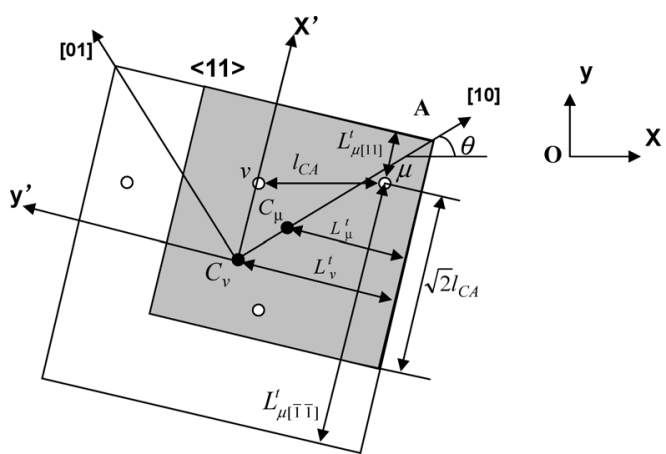

Fig. 1. Schematic diagram of 2D "decentred square" cellular automaton growth algorithm for "decentred square" growth of cell $v$ and the entrapment of its neighbor cell $\mu{ }^{3)}$ The symbols denoted by $\bigcirc$ (hollow circles) correspond to the centers of cells in the CA network, and the symbols denoted by (solid circles) are their corresponding virtual growth centers. At a certain time, the growth envelope of cell $v$ (the larger hollow square envelope centered at $C_{v}$ ) has entrapped the neighbor cell $\mu$. The sequent initial growth length of cell $\mu, L_{\mu}^{t}$, is a half side length of the truncated gray square. And the virtual growth center of cell $\mu$ is at site $C_{\mu}$ which biases the center of cell $\mu$. of one dendrite arm (i.e. [10] direction) with respect to the CA $x$-axis. The angle is among $(-\pi / 4, \pi / 4)$ from the view of the four-fold symmetry of dendritic grain. Here, $V_{C A}$ is the volume of a CA cell, $\delta n_{V}$ is the increase of grain density corresponding to undercooling increase, $d\left(\Delta T_{V}\right)$,

$$
\begin{gathered}
\frac{d n_{V}}{d\left(\Delta T_{V}^{\prime}\right)}=\frac{n_{V}}{\sqrt{2 \pi} \cdot \Delta T_{V, \sigma}} \exp \left[-\frac{1}{2}\left(\frac{\Delta T_{V}^{\prime}-\Delta T_{V}}{\Delta T_{V, \sigma}}\right)^{2}\right] \ldots \\
\delta n_{V}=n_{V}\left[\Delta T_{V}+\delta\left(\Delta T_{V}\right)\right]-n_{V}\left(\Delta T_{V}\right) \\
=\int_{\Delta T_{V}}^{\Delta T_{V}+\delta\left(\Delta T_{V}\right)} \frac{d n_{V}}{d\left(\Delta T_{V}^{\prime}\right)} d\left(\Delta T_{V}^{\prime}\right) \ldots \ldots \ldots \ldots
\end{gathered}
$$

where $n_{V}$ is the maximum nucleation density formed in the bulk of liquid. $\Delta T_{V}$ and $\Delta T_{V, \sigma}$ are the maximum undercooling and the standard deviation of the nucleation distribution, respectively. A similar procedure is applied to the heterogeneous nucleation of grains at ingot surface. Thus, two distributions are used for the heterogeneous nucleation in the bulk of liquid $\left(\Delta T_{V}, \Delta T_{V, \sigma}, n_{V}\right)$ and at ingot surface $\left(\Delta T_{S}, \Delta T_{S, \sigma}, n_{S}\right)$. The nucleation densities $n_{V}\left[\mathrm{~m}^{-3}\right]$ and $n_{S}$ $\left[\mathrm{m}^{-2}\right]$ are applied to three-dimensional geometries. The following stereological relationships were used to deduce the corresponding values $n_{V}^{*}\left[\mathrm{~m}^{-2}\right]$ and $n_{S}^{*}\left[\mathrm{~m}^{-1}\right]$ for the twodimensional (2D) cellular automation calculations: $n_{V}=$ $\sqrt{\pi / 6} \cdot\left(n_{V}^{*}\right)^{3 / 2}$ and $\left.n_{S}=\pi / 4 \cdot\left(n_{S}^{*}\right)^{2} .{ }^{1}\right)$

\subsubsection{Grain Growth}

Gandin and Rappaz ${ }^{1-3)}$ has developed three kinds of grain growth algorithms. One is "square" growth al- gorithm $^{1)}$ in which both nucleation grains and entrapped grains grow in a square envelope in two-dimensional (2D) case. It can only be applied to uniform temperature field. Since the grain orientation is strongly biased by the artificial anisotropy of CA mesh system, "dendrite tip correction" should be done to keep the original orientation of grains. The subsequent one is "rectangle" growth algorithm ${ }^{2)}$ in which the nucleation grains grow in a square envelope while the entrapped grains grow in a rectangular envelope in $2 \mathrm{D}$ case. It can maintain the original grain orientation without "correction" and can be applied to non-uniform temperature field, but it is difficult to extend to threedimensional (3D) case. Thus comes out "decentred square" growth algorithm ${ }^{3)}$ in which both the nucleation grains and the entrapped grains grow in a square envelope in $2 \mathrm{D}$ case. In the algorithm, the square envelope is always truncated to a proper size to avoid overgrowth and thus the virtual growth center for the cell usually biases its center in CA network. The "decentred square" growth algorithm can maintain the original grain orientation, describe more exactly the development of solidification microstructure in non-uniform temperature field and is easy to develop in $3 \mathrm{D}$ case. So it was chosen in the present work.

In 2D CA network, separated by a distance, $l_{C A}$, as shown in Fig. 1, a growing cell $v$ is denoted by several variables such as state (which is set as solid), crystallographic orientation, $\theta$, virtual growth center, $C_{v}$ (i.e. a center of square growth envelope), and growth length, $L_{v}^{t}$ (i.e. half side length of square growth envelope). Assuming a local uniform temperature in the scale of a cell, growth length, $L_{v}^{t}$, is given by 


$$
L_{v}^{t}=L_{v}^{t-\delta t}+\frac{v_{\text {tip }}\left(\Delta T_{v}^{t-\delta t}\right) \cdot \delta t}{\sqrt{2}}
$$

where $v_{\text {tip }}$ is the growth rate of dendrite tip. For Al-Si alloy, the dendrite tip growth kinetics can be calculated by the following approximate expression which fits well with the predictions of KGT model over a large range of undercoolings,

$$
v_{\text {tip }}(\Delta T)=A \cdot \Delta T^{n}
$$

where $n$ is $2.7, A$ is $1.7 \times 10^{-5} \mathrm{~m} / \mathrm{s} / \mathrm{K}^{n}, 5.75 \times 10^{-6} \mathrm{~m} / \mathrm{s} / \mathrm{K}^{n}$ and $2.9 \times 10^{-6} \mathrm{~m} / \mathrm{s} / \mathrm{K}^{n}$ for $\mathrm{Al}-3 \mathrm{mass} \% \mathrm{Si}, \mathrm{Al}-5 \mathrm{mass} \% \mathrm{Si}$, and $\mathrm{Al}-7 \mathrm{mass} \% \mathrm{Si}$ alloy, respectively. ${ }^{1,9)}$ Here, the values of coefficients $n$ and $A$ for $\mathrm{Al}-3 \mathrm{mass} \% \mathrm{Si}$ and $\mathrm{Al}-7 \mathrm{mass} \% \mathrm{Si}$ alloys were proposed by Gandin. ${ }^{9}$ ) The value of $A$ for Al-5mass $\% \mathrm{Si}$ alloy was, firstly fixing $n=2.7$ for convenience, determined through fitting with the $v_{\text {tip }} v s . \Delta T$ profile in Fig. 5 of Ref. 1). As shown in Fig. 2, $v_{\text {tip }}$ increases with the increase of local undercooling, $\Delta T$, and the decrease of initial solute concentration, $C^{0}$.

To simplify the entrapping judgment and the truncation, a coordinate transformation from $x o y$ system to $x^{\prime} C_{v} y^{\prime}$ system is done for a growing cell $v$. As shown in Fig. 1, in $x^{\prime} C_{v} y^{\prime}$ system, the virtual growth center, $C_{v}$, of cell $v$ is the origin, and the normal direction of growth plane $\langle 11\rangle$ for cell $v$ is $x^{\prime}$-axis. When the coordinates of its neighbor cell $\mu$ in $x^{\prime} C_{v} y^{\prime}$ system is inside the square envelope with growth length, $L_{v}^{t}$ (i.e. $\left|x_{\mu}^{\prime}\right| \leq L_{v}^{t}$ and $\left|y_{\mu}^{\prime}\right| \leq L_{v}^{t}$ ), it is entrapped. At that time, it is a random procedure for cell $\mu$ to be chosen to change state and grow up. This reflects the random growth mechanism in the actual solidification processes. Once the cell $\mu$ is chosen, it changes its state from liquid into solid and inherits the crystallographic orientation from its parent cell $v$. Its growth length, $L_{\mu}^{t}$, is firstly inherited from $L_{v}^{t}$ and then truncated to avoid overgrowth. For example, in the case shown in Fig. 1, through fixing the corner "A" which

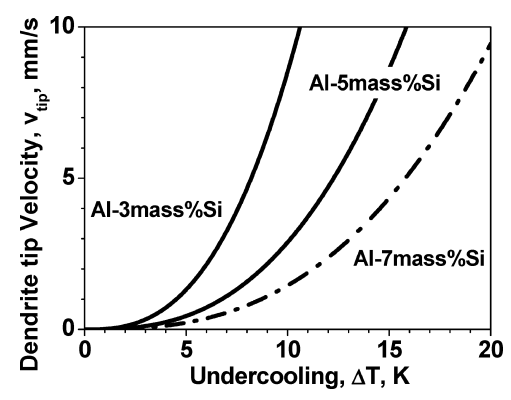

Fig. 2. Growth kinetics of dendrite tip, as calculated by using the approximate expression which fits well with the predictions of the KGT model over a large range of undercoolings, for $\mathrm{Al}-\mathrm{Si}$ alloys with three compositions. $v_{\text {tip }}=1.7 \times 10^{-5} \times(\Delta T)^{2.7} \mathrm{~m} / \mathrm{s}$ for Al-3mass $\% \mathrm{Si}, \quad v_{\text {tip }}=$ $5.75 \times 10^{-6} \times(\Delta T)^{2.7} \mathrm{~m} / \mathrm{s}$ for $\mathrm{Al}-5 \mathrm{mass} \% \mathrm{Si}, \quad v_{\text {tip }}=2.9 \times$ $10^{-6} \times(\Delta T)^{2.7} \mathrm{~m} / \mathrm{s}$ for $\mathrm{Al}-7 \mathrm{mass} \% \mathrm{Si}$. belongs to the growth envelope of cell $v$ and is the nearest corner to cell $\mu$, the growth length $L_{\mu}^{t}$ is obtained by truncating lengths of $L_{\mu[11]}^{t}$ and $L_{\mu[\overline{1} \overline{1}]}^{t}$ according to the diagonal of a CA cell, $\sqrt{2} l_{C A}$.

$$
L_{\mu}^{t}=\left[\operatorname{Min}\left(L_{\mu[11]}^{t}, \sqrt{2} l_{C A}\right)+\operatorname{Min}\left(L_{\mu[\overline{1} \overline{1}]}^{t}, \sqrt{2} l_{C A}\right)\right] / 2 \ldots
$$

$L_{\mu[11]}^{t}$ and $L_{\mu[\overline{1}]]}^{t}$ are the distance from $\mu$ to the opposite plane $\langle 11\rangle$ and $\langle\overline{1} \overline{1}\rangle$ of the growth envelope of cell $v$.

The coordinates of growth center $C_{\mu}$ are firstly calculated in $x^{\prime} C_{v} y^{\prime}$ system based on the topological relations of $L_{v}^{t}$ and $L_{\mu}^{t}$, and then they are re-transformed to the original xoy system. When all of its neighbors become solid, the cell $v$ will stop growing.

\section{Simulation Procedure}

The development of solidification microstructure in Al-Si alloy ingot with cross section size $0.03 \mathrm{~m} \times 0.03 \mathrm{~m}$ is modeled using the CA-FD coupling model. The physical properties of Al-Si alloy are shown in Table 1. The corresponding values for $\mathrm{Al}-7 \mathrm{mass} \% \mathrm{Si}$ alloy are almost the same as those adopted by Feller and Beckermann. ${ }^{16)}$ As shown in Table 1, besides the dependence of thermal conductivity on temperature $(\mathrm{K})$, both partition coefficient and latent heat of solidification are regarded as a function of $\mathrm{Si}$ concentration in the present work. Two operation parameters, $C^{0}$, and $\dot{T}$, and six nucleation parameters, $\Delta T_{V}, \Delta T_{V, \sigma}$, $n_{V}^{*}, \Delta T_{S}, \Delta T_{S, \sigma}, n_{S}^{*}$, are chosen in the calculation. Initial $\mathrm{Si}$ concentration, $C^{0}$, is set as 3 mass $\% \mathrm{Si}, 5 \mathrm{mass} \% \mathrm{Si}$ and $7 \mathrm{mass} \% \mathrm{Si}$, cooling rate in intermediate position, $\dot{T}$, is set as $0.7 \mathrm{~K} / \mathrm{s}, 2.3 \mathrm{~K} / \mathrm{s}$ and $5.0 \mathrm{~K} / \mathrm{s}$, respectively. Four nucleation parameters are fixed as $\Delta T_{V, \sigma}=0.1 \mathrm{~K}, \Delta T_{S}=1 \mathrm{~K}, \Delta T_{S, \sigma}=$ $0.1 \mathrm{~K}, n_{S}^{*}=1 / \lambda_{1}$, however, $n_{V}^{*}, \Delta T_{V}$ for heterogeneous nucleation in the bulk of liquid are changed in calculation cases, as listed in Table 2. Heat transfer coefficient, $h$, corresponding to each value of $\dot{T}$ for different $C^{0}$ is obtained beforehand through several attempts.

The numerical solution of CA-FD coupling model is performed in the following sequence:

(1) Give operation parameters: $C^{0}, h, \Delta T_{\text {superheat }}$, nucleation parameters: $\Delta T_{V}, \Delta T_{V, \sigma}, n_{V}^{*}, \Delta T_{S}, \Delta T_{S, \sigma}, n_{S}^{*}$, physical properties: $C_{p}, \kappa, \rho$, and time step: $\Delta t$.

(2) Calculate enthalpy, $H_{n+1}$, from Eq. (2) with heat transfer boundary conditions.

(3) Calculate concentration in liquid, $C_{n+1}$, from Eq. (6) with a guess of solid fraction $f_{S, n+1}$.

(4) Calculate temperature, $T_{n+1}$, from Eq. (5).

(5) Obtain accurate temperature, $T_{n+1}$, concentration, $C_{n+1}$, and solid fraction, $f_{S, n+1}$, through iterations of Eqs. (4), (5) and (6).

(6) Interpolate the temperature field from FD mesh nodes into CA cells. Calculate local undercooling for each

Table 2. Nucleation parameters required in CA model for Al-Si alloy.

\begin{tabular}{lccccc}
\hline $\begin{array}{l}\text { Max nucleation } \\
\text { undercooling in } \\
\text { the bulk, }\end{array}$ & $\begin{array}{l}\text { Standard } \\
\text { deviation in } \\
\text { the bulk, } \\
\Delta T_{V}, \mathrm{~K}\end{array}$ & $\begin{array}{l}\text { Nucleation } \\
\text { density in the } \\
\text { bulk, } \\
n_{V, \sigma}^{*}, m^{-2}\end{array}$ & $\begin{array}{l}\text { Max nucleation } \\
\text { undercooling at } \\
\text { surface, } \\
\Delta T_{S}, \mathrm{~K}\end{array}$ & $\begin{array}{l}\text { Standard } \\
\text { deviation at } \\
\text { the surface, } \\
\Delta T_{S, \sigma}, \mathrm{K}\end{array}$ & $\begin{array}{l}\text { Nucleation } \\
\text { density at the } \\
\text { surface, } \\
n_{S}^{*}, m^{-1}\end{array}$ \\
\hline Parameter fitting & 0.1 & $\begin{array}{l}\text { Parameter } \\
\text { fitting }\end{array}$ & 1 & 0.1 & $n_{S}^{*}=1 / \lambda_{1}$ \\
\hline
\end{tabular}



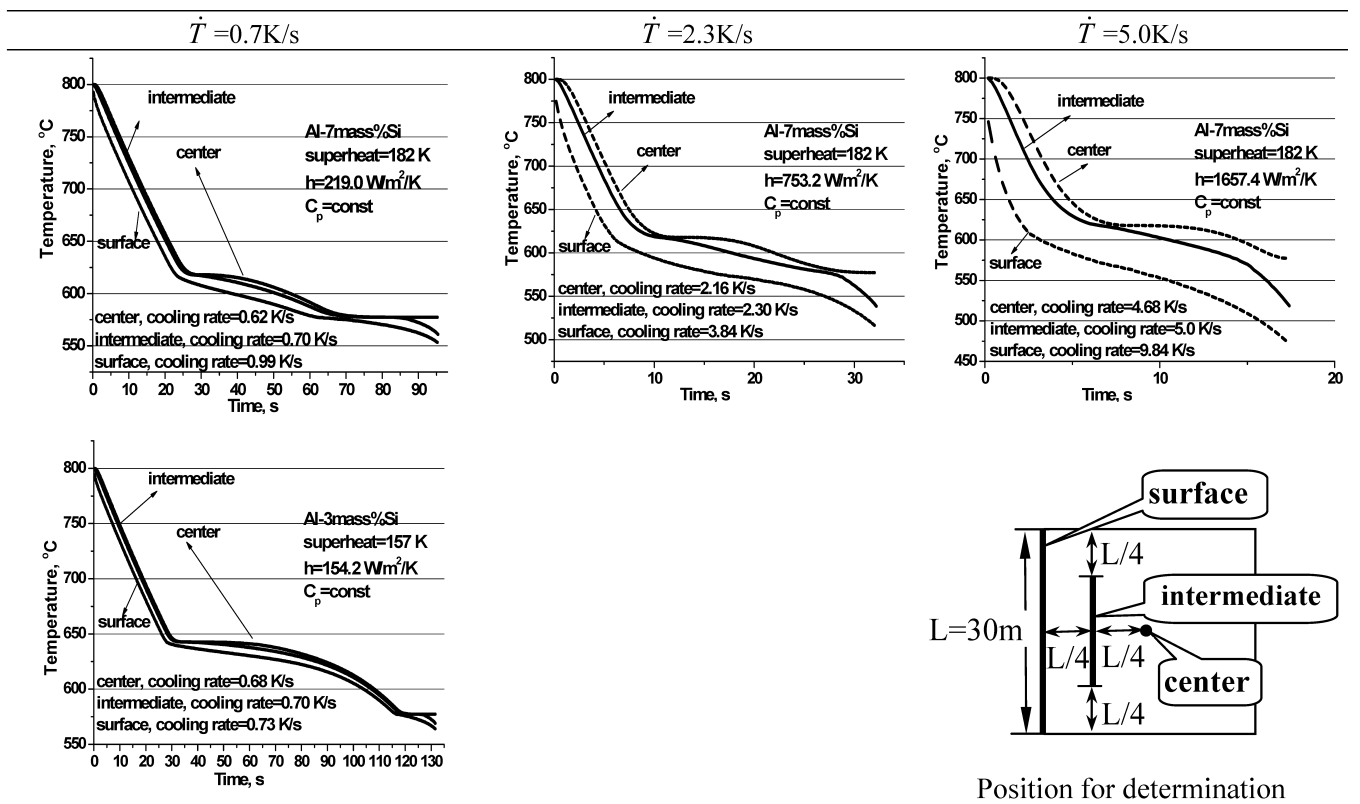

Position for determination of the cooling rate

Fig. 3. Calculated cooling curves for $\mathrm{Al}-7 \mathrm{mass} \% \mathrm{Si}$ and $\mathrm{Al}-3 \mathrm{mass} \% \mathrm{Si}$ ingots with different cooling rate in intermediate position $\dot{T}$.

CA cell.

(7) Calculate the nucleation probability by the increase of local undercooling in two CA time step, $\Delta T_{n}, \Delta T_{n+1}$, from Eqs. (8) and (9).

(8) Calculate the grain growth by "decentred square" growth algorithm from Eqs. (10), (11) and (12).

(9) Return to step (2) until the solidification is completed in the entire domain $\left(f_{S}=1\right.$ for all FD nodes).

\section{Results and Discussions}

\subsection{Cooling Curves}

Figure 3 shows calculated cooling curves for Al$7 \mathrm{mass} \% \mathrm{Si}$ and $\mathrm{Al}-3 \mathrm{mass} \% \mathrm{Si}$ ingots with different cooling rates in intermediate position, $\dot{T}$. Heat transfer coefficients, $h$ corresponding to these cases are also shown.

Generally, the slope of the curve becomes smaller temporarily due to the appearance of primary phase and eutectic phase. After the completion of solidification, the slope returns to the original state. Here the cooling rates at three positions (intermediate, center and surface of ingot) are defined by the ratio of temperature decrease to solidification time. The solidification time decreases with the increase of Si concentration, $C^{0}$, with the increase of cooling rate in intermediate position, $\dot{T}$, and with the position closer to ingot surface due to the efficiency of heat transfer.

\subsection{Morphologies of Solidification Microstructure}

The grain growth is stopped once the dendrites of primary phase collide with each other. The collision point is recognized as the so-called "grain boundary". The linked grains whose orientation difference is greater than $1.8 \mathrm{deg}$. are regarded as two distinguished grains.

\subsubsection{Effects of Parameters on Solidification Morpholo- gies}

Figure 4 shows the final solidification microstructures of
$\mathrm{Al}-7 \mathrm{mass} \% \mathrm{Si}, \mathrm{Al}-5 \mathrm{mass} \% \mathrm{Si}$ and $\mathrm{Al}-3 \mathrm{mass} \% \mathrm{Si}$, as calculated using the CA-FD coupling model. The parameter effects on the size of columnar and equiaxed grains are examined carefully. Firstly, the effects of operation parameters $\left(C^{0}\right.$ and $\left.\dot{T}\right)$ and nucleation parameters $\left(\Delta T_{V}\right.$ and $\left.n_{S}^{*}\right)$ on the size (length and width) of columnar grains can be recognized. The length of columnar grains increases clearly with the increase of nucleation undercooling, $\Delta T_{V}$, with the decrease of $\mathrm{Si}$ concentration, $C^{0}$, and with the decrease of cooling rate in intermediate position, $\dot{T}$. This tendency comes from the dendrite tip growth kinetics which leads to the average length of columnar grain. Briefly, the average length of columnar grain is directly proportional to the growth rate of dendrite tip, $v_{\text {tip }}\left(\Delta T, C^{0}\right)$, and inversely proportional to $\dot{T}{ }^{1)}$ In addition, due to the implicit relationship between nucleation density, $n_{S}^{*}\left(\equiv 1 / \lambda_{1}\right)$, and cooling rate at ingot surface, $\dot{T}_{\text {Surface }}: \lambda_{1}=220 \times 10^{-6} \times\left(\dot{T}_{\text {Surface }}\right)^{-0.55}$, the width of columnar grain increases clearly with the decrease of $\dot{T}$. Here, it is noted that $n_{S}^{*} \geq 1 / \lambda$, i.e. nucleation density at ingot surface is usually greater than columnar grain density $\left(1 / \lambda_{1}\right)$ due to the competition of the nucleation and the grain growth.

Secondly, the effects of operation parameters $\left(C^{0}, \dot{T}\right)$ and nucleation parameters $\left(\Delta T_{V}, n_{V}^{*}\right)$ on the size of equiaxed grains can also be recognized from Fig. 4. The size of equiaxed grains decreases clearly with the increase of nucleation density, $n_{V}^{*}$; while it decreases somewhat with the increase of nucleation undercooling, $\Delta T_{V}$, only for Al-3mass\%Si alloy, as shown in Fig. 5. This tendency comes from the competition of the nucleation and the grain growth. Consequently, only nucleation density in the bulk liquid will control the size of equiaxed grains in the case of comparatively low dendrite tip growth rate. Here, the equiaxed grain size was evaluated by the grain size analysis software WINROOF. The size of each grain was determined as the area-equivalent diameter. 
ISIJ International, Vol. 49 (2009), No. 7

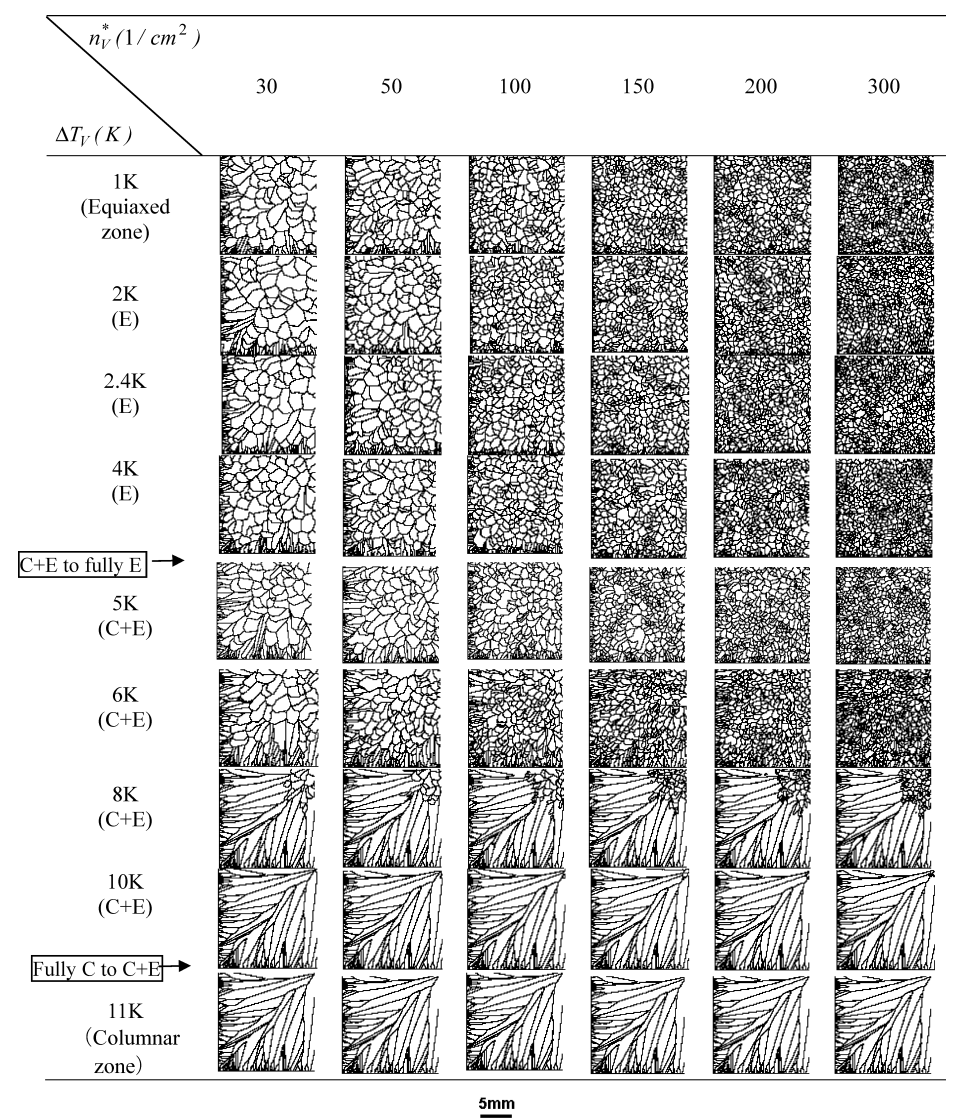

(a) $\mathrm{Al}-7 \mathrm{mass} \% \mathrm{Si}, \dot{\mathrm{T}}=0.7 \mathrm{~K} / \mathrm{s}$

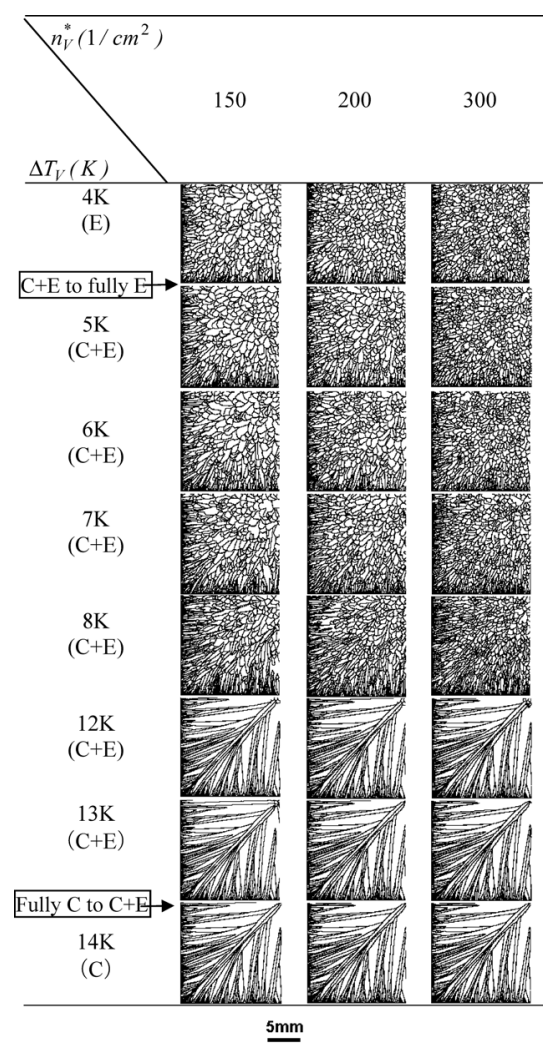

(c) $A l-7$ mass $\% S i, \dot{T}=5.0 K / s$

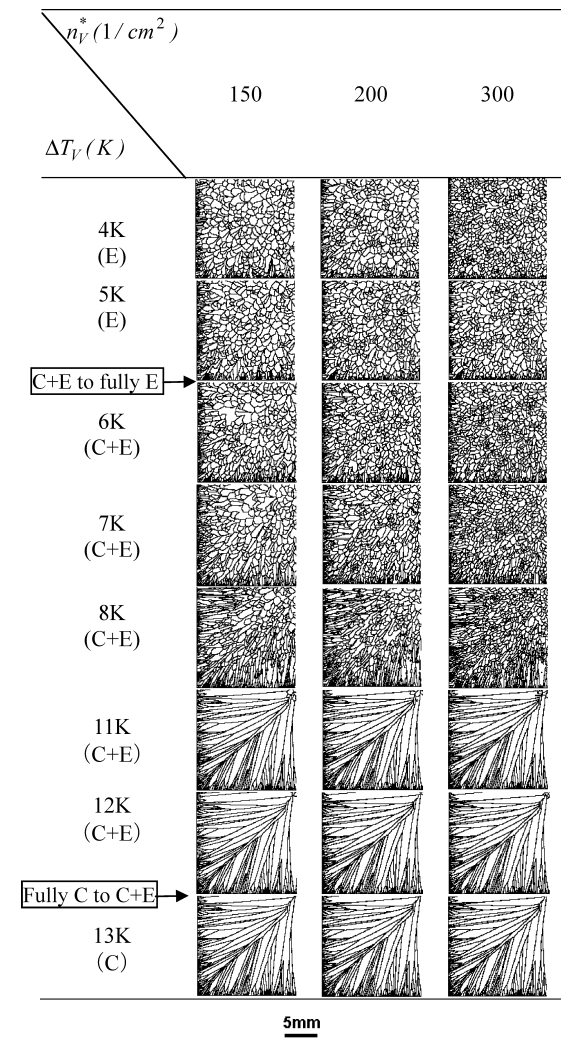

(b) $\mathrm{Al}-7 \mathrm{mass} \% \mathrm{Si}, \dot{T}=2.3 \mathrm{~K} / \mathrm{s}$

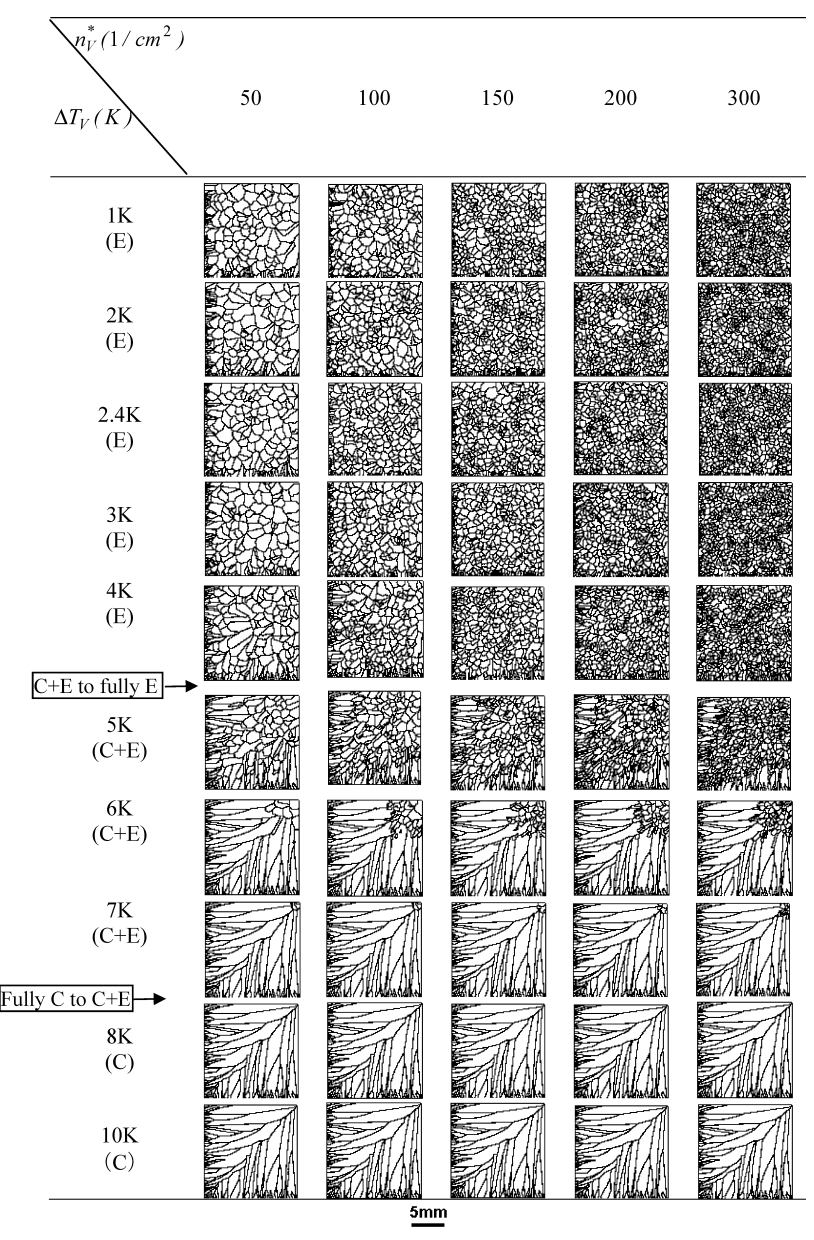

(d) $A l-5 m a s s \% S i, \dot{T}=0.7 K / s$

Fig. 4. 


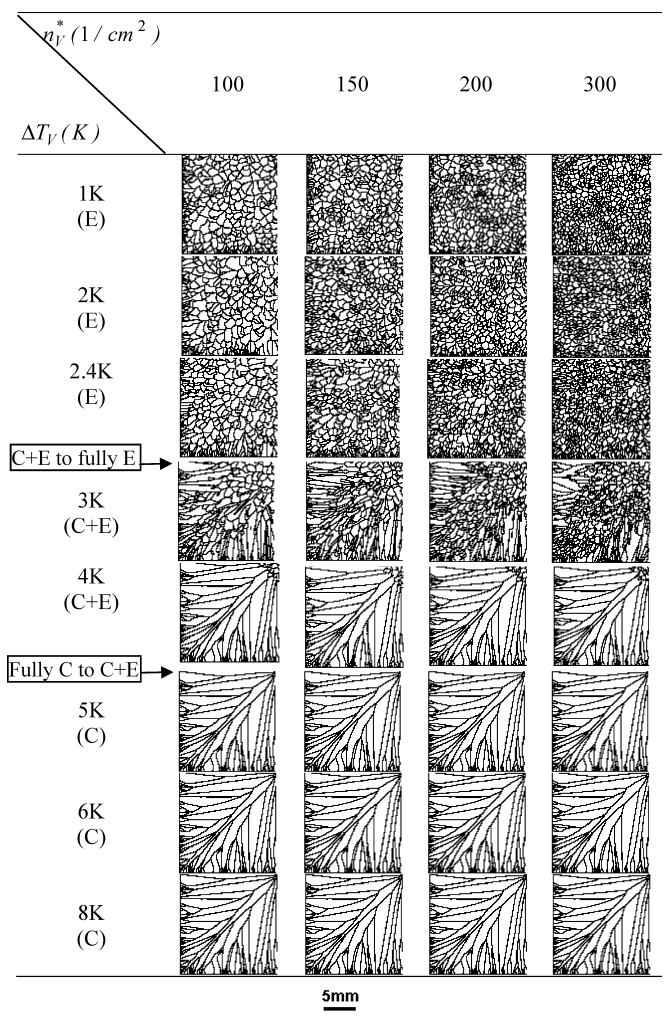

(e) $\mathrm{Al}-3 \mathrm{mass} \% \mathrm{Si}, \dot{T}=0.7 \mathrm{~K} / \mathrm{s}$

Fig. 4. The final solidification microstructures of $\mathrm{Al}-7 \mathrm{mass} \% \mathrm{Si}$, $\mathrm{Al}-5 \mathrm{mass} \% \mathrm{Si}$ and $\mathrm{Al}-3 \mathrm{mass} \% \mathrm{Si}$ alloy ingots, as calculated by the CA-FD coupling model.

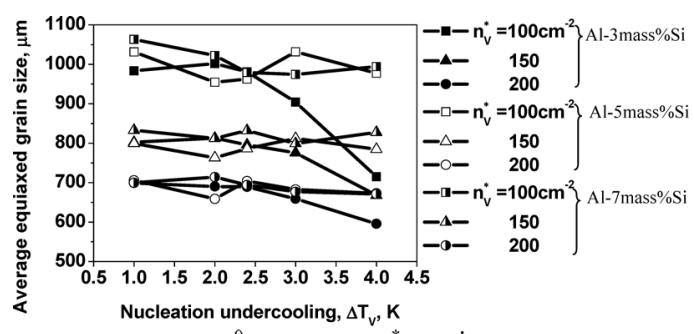

(a) Effects of $C^{0}, \Delta T_{V}$ and $n_{V}^{*}$ at $\dot{T}=0.7 \mathrm{~K} / \mathrm{s}$

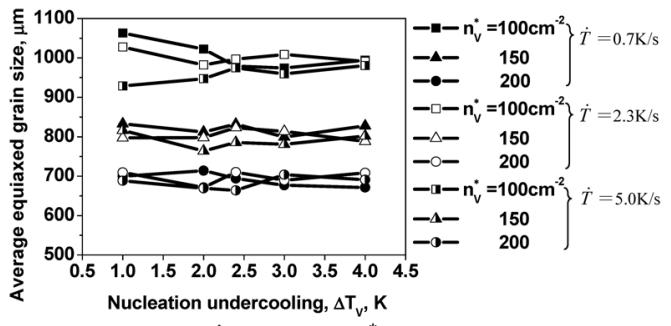

(b) Effects of $\dot{T}, \Delta T_{V}$ and $n_{V}^{*}$ for Al-7mass\% $\%$ Si alloy

Fig. 5. Effects of operation parameters $\left(C^{0}, \dot{T}\right)$ and nucleation parameters $\left(\Delta T_{V}, n_{V}^{*}\right)$ on the size of the equiaxed grains, as calculated by the CA-FD coupling model.

4.2.2. Identification of Nucleant and Estimation of Nucleation Density in Actual Al-Si Alloy

The effects of impurities on the grain size in actual Al-Si alloy are discussed in the present work by using the CA-FD coupling model, because it is found that nucleation density in the bulk liquid, $n_{V}^{*}$ mainly control the size of the equiaxed grains in the case of $\Delta T_{V} \leq 3 \mathrm{~K}$ for Al-Si alloy.

Figure 6 shows the effects of nucleation density, $n_{V}^{*}$, nucleation undercooling, $\Delta T_{V}$, and $\mathrm{Si}$ concentration, $C_{0}$, on

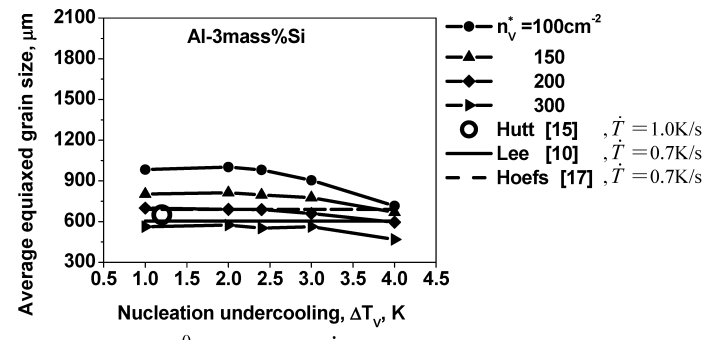

(a) $C^{0}=3 \mathrm{mass} \% \mathrm{Si}, \dot{T}=0.7 \mathrm{~K} / \mathrm{s}$

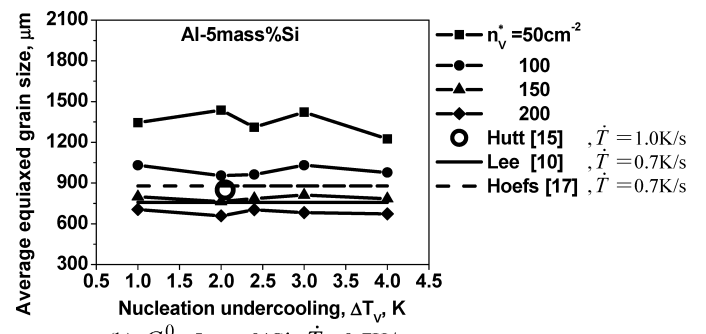

(b) $C^{0}=5 \mathrm{mass} \% \mathrm{Si}, \dot{T}=0.7 \mathrm{~K} / \mathrm{s}$

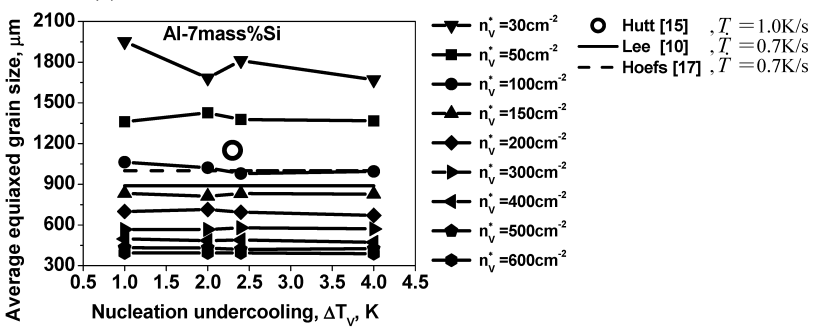

(c) $C^{0}=7 \mathrm{mass} \% \mathrm{Si}, \dot{T}=0.7 \mathrm{~K} / \mathrm{s}$

Fig. 6. Effects of nucleation density $n_{V}^{*}$, nucleation undercooling $\Delta T_{V}$ and $\mathrm{Si}$ concentration $C^{0}$ on the grain size under cooling rate $\dot{T}=0.7 \mathrm{~K} / \mathrm{s}$, as calculated by using the CA-FD coupling model, and the experimental data of grain size for actual Al-Si alloys.

grain size under cooling rate in intermediate position $\dot{T}=0.7 \mathrm{~K} / \mathrm{s}$, as calculated using the CA-FD coupling model, and the experimental data of grain size in actual Al-Si alloy by Hutt et al. ${ }^{15)}(\dot{T}=1.0 \mathrm{~K} / \mathrm{s})$, Lee et al. ${ }^{10)}(\dot{T}=0.7 \mathrm{~K} / \mathrm{s})$ and Hoefs et $a l .{ }^{17)}(\dot{T}=0.7 \mathrm{~K} / \mathrm{s})$. The experimental data of grain size is in the range of 600 to $700 \mu \mathrm{m}$ for $\mathrm{Al}-3 \mathrm{mass} \% \mathrm{Si}$ alloy, 750 to $900 \mu \mathrm{m}$ for $\mathrm{Al}-5 \mathrm{mass} \% \mathrm{Si}$ alloy and 900 to $1200 \mu \mathrm{m}$ for $\mathrm{Al}-7 \mathrm{mass} \% \mathrm{Si}$ alloy. Regarding nucleation undercoolings, Hutt et al. ${ }^{15)}$ reported $\Delta T_{V}=1.2 \mathrm{~K}$ for Al-3mass $\% \mathrm{Si}$ alloy, $\Delta T_{V}=2.05 \mathrm{~K}$ for $\mathrm{Al}-5 \mathrm{mass} \% \mathrm{Si}$ alloy and $\Delta T_{V}=2.3 \mathrm{~K}$ for $\mathrm{Al}-7 \mathrm{mass} \% \mathrm{Si}$ alloy. Murty ${ }^{18)}$ also reported $\Delta T_{V}=1.9 \mathrm{~K}$ for $\mathrm{Al}-7 \mathrm{mass} \% \mathrm{Si}$ alloy. Those results indicate that with the increase of impurity concentration caused by the increase of Al concentration in actual Al-Si alloy, the heterogeneous nucleation occurs easier and then $\Delta T_{V}$ decreases.

Firstly, from the agreement between the calculated average equiaxed grain sizes and the experimental ones in Fig. 6 , the nucleation densities in Hutt's, Lee's and Hoefs' experiments are roughly evaluated as $n_{V}^{*}=200$ to $300 \mathrm{~cm}^{-2}$ $\left(n_{V}=2050\right.$ to $3760 \mathrm{~cm}^{-3}$ ) for $\mathrm{Al}-3 \operatorname{mass} \% \mathrm{Si} ; n_{V}^{*}=100$ to $200 \mathrm{~cm}^{-2}\left(n_{V}=720\right.$ to $\left.2050 \mathrm{~cm}^{-3}\right)$ for $\mathrm{Al}-5 \mathrm{mass} \% \mathrm{Si}$ and $n_{V}^{*}=50$ to $150 \mathrm{~cm}^{-2} \quad\left(n_{V}=260\right.$ to $\left.1330 \mathrm{~cm}^{-3}\right)$ for $\mathrm{Al}-$ 7 mass $\%$ Si. Secondly, it is found that the impurity element $\mathrm{Fe}$ in the form $\mathrm{Al}_{3} \mathrm{Fe}$ might act as a nucleant for heterogeneous nucleation, because actual Al-Si alloy is prepared using commercial purity $\mathrm{Al}$ ( $\mathrm{Al}$ : 99.7 mass\%, Fe: 0.16 mass $\%$, Si: 0.11 mass $\%)^{19)}$ and consequently there is 


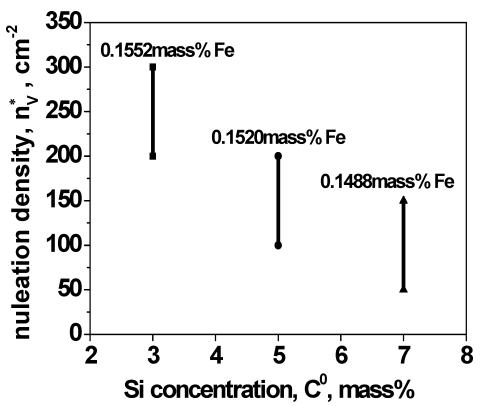

Fig. 7. Relationship among $\mathrm{Si}$ concentration $C^{0}$, Fe concentration and nucleation density $n_{V}^{*}$ in actual Al-Si alloy prepared by using commercial purity Al.

$0.1552 \mathrm{mass} \% \mathrm{Fe}$ for $\mathrm{Al}-3 \%$ massSi, $0.152 \mathrm{mass} \% \mathrm{Fe}$ for $\mathrm{Al}-5 \mathrm{mass} \% \mathrm{Si}$ and 0.1488 mass $\% \mathrm{Fe}$ for $\mathrm{Al}-7 \mathrm{mass} \% \mathrm{Si}$, respectively. Actually, the grain size of $\mathrm{Al}-7 \mathrm{mass} \% \mathrm{Si}$ alloy is in the range of 300 to $400 \mu \mathrm{m}$ with 0.1 mass $\%$ addition of $\mathrm{Fe}$ (i.e. total $0.2488 \mathrm{mass} \% \mathrm{Fe}) .{ }^{18,19)}$ It corresponds to $n_{V}^{*}=600 \mathrm{~cm}^{-2}\left(n_{V}=10630 \mathrm{~cm}^{-3}\right)$ as indicated in Fig. $6(\mathrm{c})$. Relationship among Si concentration, $C^{0}$, Fe concentration and nucleation density, $n_{V}^{*}$, in actual Al-Si alloy prepared by using commercial purity $\mathrm{Al}$ is summarized in Fig. 7.

\subsection{Criteria for Columnar to Equiaxed Transition (CET)}

Here, the comparison is made for Al-Si alloy between the CET criteria based on the solidification path predicted by the CA-FD coupling model and one based on the critical temperature gradient conditions predicted by Hunt's model and Stefanescu's model.

\subsubsection{CET Criteria from Solidification Microstuctures by CA-FD Coupling Model}

The CET is controlled by the competition of the nucleation and the grain growth process, as described in Sec. 4.2.1. Consequetly, three steady-state growth conditions occur: (1) fully columnar growth (fully C), (2) mixed columnar/equiaxed growth $(\mathrm{C}+\mathrm{E})$ and (3) fully equiaxed growth (fully E).

\section{(1) CET for Fully C}

From the solidification microstructures shown in Fig. 4, it is found that the influence of nucleation density, $n_{V}^{*}$, on the transition from fully $\mathrm{C}$ to $\mathrm{C}+\mathrm{E}$ is unclear in the range of $n_{V}^{*}=30$ to $300 \mathrm{~cm}^{-2}$, while the transition from fully $\mathrm{C}$ to $\mathrm{C}+\mathrm{E}$ occurs easily with the decrease of nucleation undercooling, $\Delta T_{V}$, with the increase of Si concentration, $C^{0}$, and with the increase of cooling rate in intermediate position, $\dot{T}$. Thus, it indicates that the transition from fully $\mathrm{C}$ to $\mathrm{C}+\mathrm{E}$ is controlled almost uniquely by the growth rate of dendrite tip. Figure 8 shows the dependence of the CET criteria (transition from fully $\mathrm{C}$ to $\mathrm{C}+\mathrm{E}$ ) on $\Delta T_{V}, C^{0}$ and $\dot{T}$ based on the solidification microstructures in Fig. 4.

\section{(2) CET for Fully E}

From the solidification microstructures shown in Fig. 4, it is found that the influence of nucleation density, $n_{V}^{*}$, on the transition from $\mathrm{C}+\mathrm{E}$ to fully $\mathrm{E}$ is clear in the range of $n_{V}^{*}=30$ to $100 \mathrm{~cm}^{-2}$, but unclear in the range of $n_{V}^{*}=150$ to $300 \mathrm{~cm}^{-2}$; and the transition from $\mathrm{C}+\mathrm{E}$ to fully $\mathrm{E}$ occurs

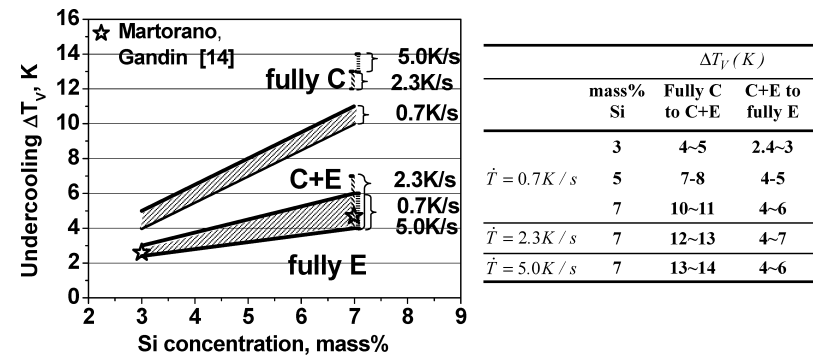

Fig. 8. Dependence of the CET criteria on $\Delta T_{V}, C^{0}$ and $\dot{T}$ for fully columnar growth (fully $C$ ) and for fully equiaxed growth (fully E), based on the solidification microstructure predicted by the CA-FD coupling model.

easily with the decrease of nucleation undercooling, $\Delta T_{V}$, with the increase of Si concentration, $C^{0}$. In addition, the influence of cooling rate in intermediate position, $\dot{T}$, on transition from $\mathrm{C}+\mathrm{E}$ to fully $\mathrm{E}$ was unclear. Thus, it indicates that the transition from $\mathrm{C}+\mathrm{E}$ to fully $\mathrm{E}$ is controlled by both the nucleation and the growth rate of the dendrite tip. Figure 8 also shows the dependence of the CET criteria (transition from $\mathrm{C}+\mathrm{E}$ to fully $\mathrm{E}$ ) on $\Delta T_{V}, C^{0}$ and $\dot{T}$ based on the solidification microstructures in Fig. 4. The range of $\Delta T_{V}$ corresponding to transition from $\mathrm{C}+\mathrm{E}$ to fully $\mathrm{E}$ agrees well with that by Martorano and Gandin, ${ }^{14)}$ which is $2.6 \mathrm{~K}$ for $\mathrm{Al}-3$ mass $\% \mathrm{Si}$ and $4.7 \mathrm{~K}$ for $\mathrm{Al}-7 \mathrm{mass} \% \mathrm{Si}$, as shown in Fig. 8.

\subsubsection{CET Criteria by Hunt's Model}

In Hunt's model, ${ }^{20)}$ the critical temperature gradient conditions for fully equiaxed (fully E) and for fully columnar growth (fully C) are approximately given by

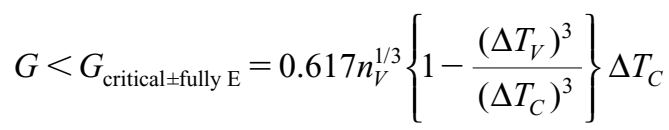

for fully equiaxed growth

$$
G>G_{\text {critical ffully C }}=0.617\left(100 n_{V}\right)^{1 / 3}\left\{1-\frac{\left(\Delta T_{V}\right)^{3}}{\left(\Delta T_{C}\right)^{3}}\right\} \Delta T_{C}
$$

for fully columner growth.

where $G$ is the temperature gradient in solid/liquid (S/L) interface expressed in forward or backward difference approximation at the interface (see Fig. 9). $n_{V}$ is the nucleation densities for three-dimensional geometry. $\Delta T_{C}$ is the local undercooling ahead of columnar dendrite front, ${ }^{21)}$

$$
\Delta T_{C}=2\left\{-\frac{2 m\left(1-k^{S / L}\right) C_{0} \bar{v}_{L} \Gamma}{D_{L}}\right\}^{1 / 2}=\left\{\frac{\bar{v}_{L} C_{0}}{A}\right\}^{1 / 2} \ldots
$$

where $\bar{v}_{L}$ is the solid/liquid (S/L) interface velocity. It is approximately set as the moving velocity of liquidus isotherm (see Fig. 10). $A=D_{L} /\left(4 \cdot(-2) m\left(1-k^{S / L}\right) \Gamma\right)\left[m \operatorname{mass} \% \mathrm{~s}^{-1}\right.$ $\mathrm{K}^{-2}$ ] is a constant, and physical properties are listed in Table 1 .

The dependence of the CET criteria on nucleation undercooling, $\Delta T_{V}$, and Si concentration, $C^{0}$, is discussed under nucleation density, $n_{V}^{*}=150 \mathrm{~cm}^{-2}$ and cooling rate in inter- 


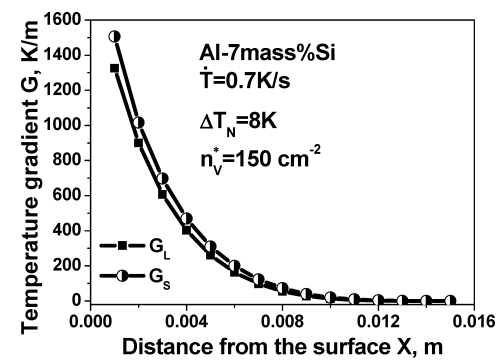

Fig. 9. Distributions of temperature gradient at solid/liquid interface. At time $t_{l}$ when position $x_{l}$ becomes solid, temperature gradient is evaluated by the sequent temperatures of the closest positions forward and backward: $G_{L}=G_{\text {forward } l}=\left(T_{l+2}\left(t_{l}\right)-T_{l+1}\left(t_{l}\right)\right) /\left(x_{l+2}-x_{l+1}\right), G_{S}=G_{\text {back }, l}=$ $\left(T_{l}\left(t_{l}\right)-T_{l-1}\left(t_{l}\right)\right) /\left(x_{l}-x_{l-1}\right)$.

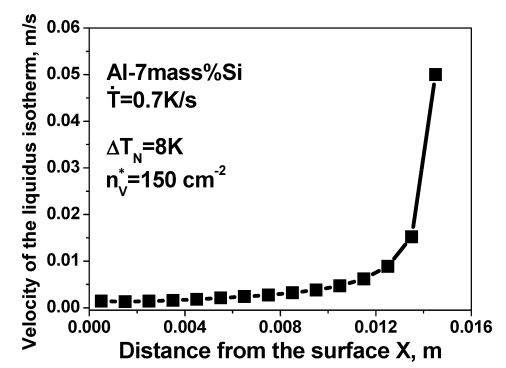

Fig. 10. Moving velocity of solid/liquid interface. It is set as the moving velocity of the liquidus isotherm, that is, the ratio of the distance between two consecutive positions where the liquidus isotherm travels to the time elapsed, $\bar{v}_{L}=\left(x_{l+1}-x_{l}\right) /\left(t_{l+1}-t_{l}\right)$. It is drawn at the middle of the two adjacent positions, $\left(x_{l}+x_{l+1}\right) / 2$.

mediate position, $\dot{T}=0.7 \mathrm{~K} / \mathrm{s}$. Comparison of the CET criteria based on the solidification path predicted by the CA-FD coupling model and the critical temperature gradient conditions predicted by Hunt's model for $\mathrm{Al}-7 \mathrm{mass} \% \mathrm{Si}$ alloy, $\mathrm{Al}-5 \mathrm{mass} \% \mathrm{Si}$ and $\mathrm{Al}-3 \mathrm{mass} \% \mathrm{Si}$ alloy are shown in Fig. 11 to Fig. 13 .

The symbols denoted by $\triangle, \mathbf{\square}$ and $\ominus$ on the solidification path by the CA-FD coupling model represent the fully columnar growth (fully $\mathrm{C}$ ), the fully equiaxed growth (fully E) and the mixed columnar and equiaxed growth $(C+E)$, respectively. As illustrated, the CET criteria based on the solidification path by CA-FD coupling model are strongly dependent on both $\Delta T_{V}$ and $C^{0}$. The curves of the critical temperature gradient conditions by Hunt's model (the curves labeled $G$ _fully E and $G$ _fully C) are also strongly dependent on both $\Delta T_{V}$ and $C^{0}$. To well illustrate the CET, the solidification microstructures at typical stages of solidification are also given below the CET map.

As shown in Fig. 11 to Fig. 13, the good agreement is obtained between these two. Hunt's assumptions based on steady state seem to hold approximately, because the temperature field is changed slowly in the case of cooling rate $\dot{T}=0.7 \mathrm{~K} / \mathrm{s}$.

\subsubsection{CET Criteria by Stefanescu's Model}

Stefanescu ${ }^{21)}$ also proposed the critical temperature gradient conditions for CET as follows,

$$
G \leq G_{\mathrm{CET}}=3.22\left[\frac{n_{V}}{f_{S, \mathrm{coh}}}\left(1-\frac{v_{L}}{\bar{v}_{L}}\right)\right]^{1 / 3} \frac{\mu_{e}}{\mu_{c}} \Delta T .
$$
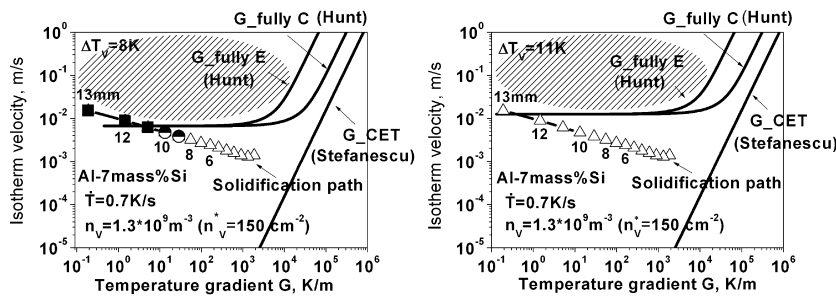

- Fully equiaxed zone, $\ominus$-Columnar and equiaxed grain mixed zone, $\triangle$-Fully columnar zone

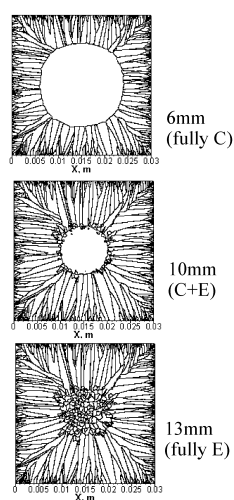

(a) $\Delta T_{V}=8 \mathrm{~K}$

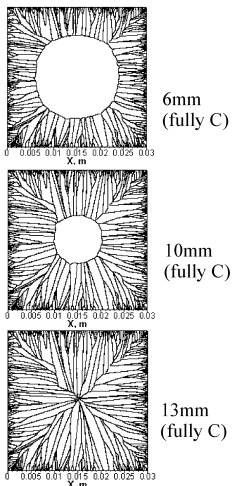

(b) $\Delta T_{V}=11 \mathrm{~K}$
Fig. 11. Comparisons between the CET criteria based on the solidification path predicted by the CA-FD coupling model and one based on the critical temperature gradient conditions predicted by Hunt's model and Stefanescu's model for $\mathrm{Al}-7$ mass\%Si alloy. Upper part: dependence of the CET criteria on $\Delta T_{V}$ and $C^{0}$ under $n_{V}^{*}=150 \mathrm{~cm}^{-2}$ and $\dot{T}=0.7 \mathrm{~K} / \mathrm{s}$. Lower part: solidification microstructures at typical stages of solidification.
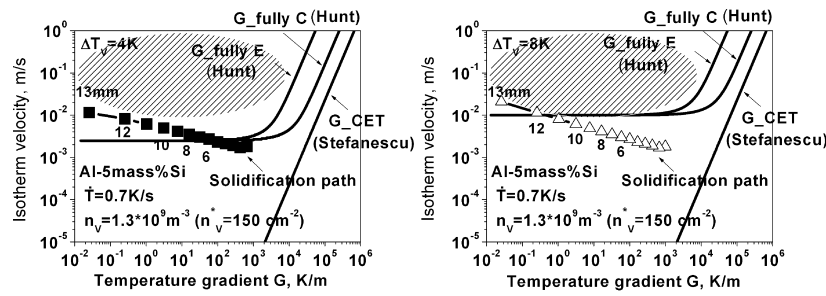

- Fully equiaxed zone -Colum

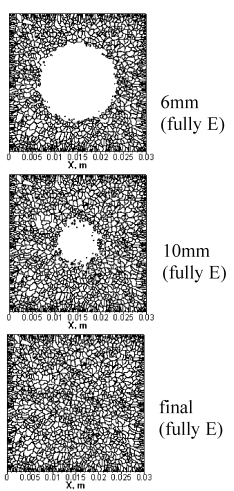

(a) $\Delta T_{V}=4 K$

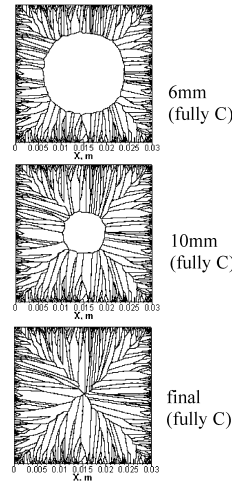

(b) $\Delta T_{V}=8 K$
Fig. 12. Comparisons between the CET criteria based on the solidification path predicted by the CA-FD coupling model and one based on the critical temperature gradient conditions predicted by Hunt's model and Stefanescu's model for $\mathrm{Al}-5 \mathrm{mass} \% \mathrm{Si}$ alloy. Upper part: dependence of the CET criteria on $\Delta T_{V}$ and $C^{0}$ under $n_{V}^{*}=150 \mathrm{~cm}^{-2}$ and $\dot{T}=0.7 \mathrm{~K} / \mathrm{s}$. Lower part: solidification microstructures at typical stages of solidification. 

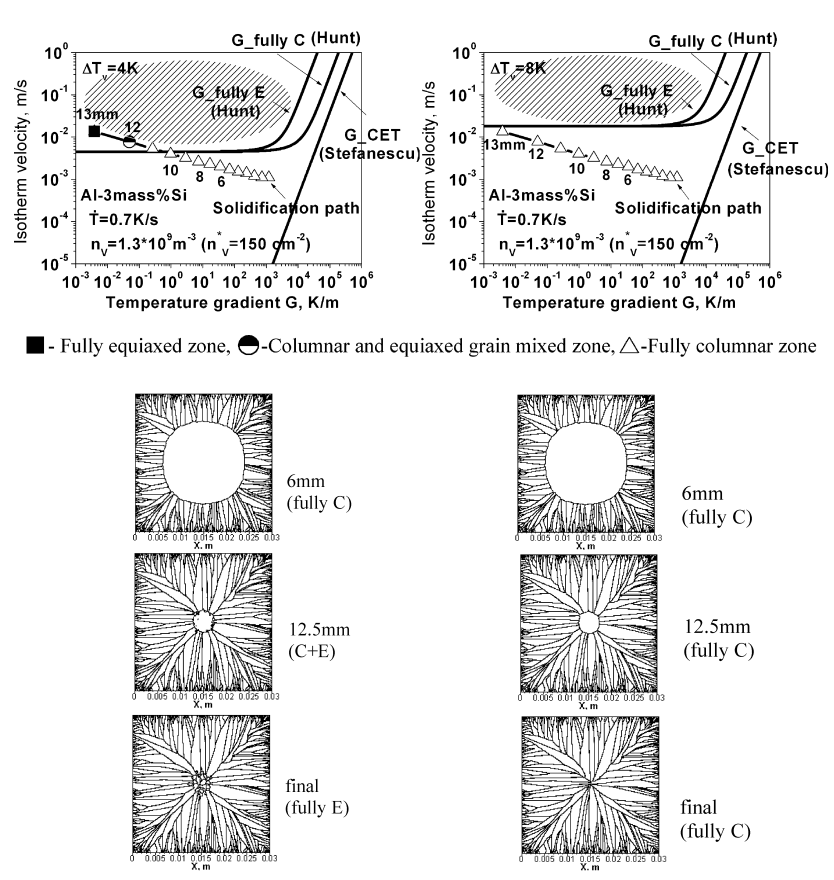

(a) $\Delta T_{V}=4 K$

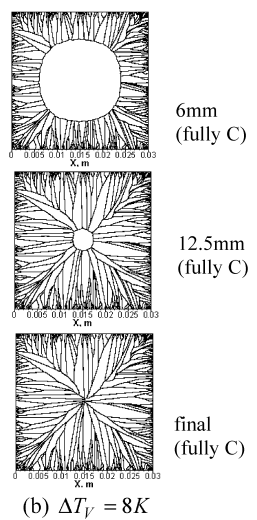

Fig. 13. Comparisons between the CET criteria based on the solidification path predicted by the CA-FD coupling model and one based on the critical temperature gradient conditions predicted by Hunt's model and Stefanescu's model for $\mathrm{Al}-3$ mass $\% \mathrm{Si}$ alloy. Upper part: dependence of the CET criteria on $\Delta T_{V}$ and $C^{0}$ under $n_{V}^{*}=150 \mathrm{~cm}^{-2}$ and $\dot{T}=0.7 \mathrm{~K} / \mathrm{s}$. Lower part: solidification microstructures at typical stages of solidification.

where $f_{S \text {,coh }}$, the coherency solid fraction, is the solid fraction when dendrite coherency is established during columnar grain growth process. A reasonable limit is assuming that $f_{S \text {, ritical }}=f_{S \text {, coh }}$ with $f_{S \text {, critical }}$ the critical solid fraction for CET. Stefanescu recommended a typical value of $f_{S, \text { coh }}=0.2$ to 0.4 . In the present work, $f_{S, \text { coh }}=0.3 . v_{L}$ is the flow velocity by convection (here $v_{L}=0$ ). $\mu_{e}$ and $\mu_{c}$ are the growth coefficient of equiaxed and columnar dendrites, respectively. In steady-state columnar growth, $\mu_{c}=\left(k^{S / L} D_{L}\right) /\left\{\pi^{2} \Gamma m\left(k^{S / L}-\right.\right.$ 1) $\left.C_{0}\right\}$ and $\mu_{e}=0.5 \mu_{c}$, when the thermal undercooling is ignored. The local undercooling in steady-state columnar growth can be deduced as $\Delta T=\sqrt{\bar{v}_{L} / \mu_{c}}$ from the expression of solid/liquid $(\mathrm{S} / \mathrm{L})$ interface velocity $\bar{v}_{L}=\mu_{c} \Delta T^{2}$. Stefanescu's expression was deduced without the assumption of steady-state columnar growth, although it includes the original idea of coherency solid fraction and liquid convection.

The critical temperature gradient conditions by Stefanescu's model for Al-7mass\%Si alloy, Al-5mass\%Si and Al-3mass \% Si alloys are added in Fig. 11 to Fig. 13. The curves of the critical temperature gradient conditions by Stefanescu's model (the curves labeled $G_{-}$CET) are dependent on $C^{0}$, but independent on $\Delta T_{V}$, because the term of $\Delta T_{V}$ is not included in Stefanescu's expression.

\section{Conclusions}

A CA-FD coupling model has been developed to analyze the development of solidification microstructure and the CET criteria for Al-Si alloy. The validation of the model was achieved with the help of previous experiments. The following conclusions can be obtained:

(1) Through the examination of the effects of operation parameters and nucleation parameters on solidification morphologies, the length of columnar grains is controlled by the dendrite tip growth kinetics, and the width of columnar grains is controlled by the implicit relationship between nucleation density and cooling rate at ingot surface. The size of equiaxed grains is controlled by the competition of the nucleation and the grain growth.

(2) With the controllability of nucleation density in the bulk of liquid for equiaxed grain size, the nucleant and the nucleation density in actual Al-Si alloy are estimated. The impurities in actual Al-Si alloy prepared by using commercial purity $\mathrm{Al}$, especially the element $\mathrm{Fe}$ in the form of $\mathrm{Al}_{3} \mathrm{Fe}$, might act as a heterogeneous nucleant and do contribute to the grain refinement.

(3) The CET criteria based on both the solidification path predicted by the CA-FD coupling model and the curves of the critical temperature gradient conditions predicted by Hunt's model are strongly dependent on nucleation undercooling and Si concentration. A good agreement is obtained between these two.

\section{Acknowledgements}

The work is supported by "the 111 Project [B07015]" and "Natural Science Foundation of Liaoning Province [20031010] and [20072033]".

\section{REFERENCES}

1) M. Rappaz and Ch.-A. Gandin: Acta Metall., 41 (1993), 345.

2) Ch.-A. Gandin and M. Rappaz: Acta Metall. Mater., 42 (1994), 2233.

3) Ch.-A. Gandin and M. Rappaz: Acta Mater., 45 (1997), 2187.

4) Ch.-A. Gandin, J.-L. Desbiolles, M. Rappaz and Ph. Thevoz: Metall. Mater. Trans. A, 30 (1999), 3153.

5) G. Guillemot, Ch.-A. Gandin, H. Combeau and R. Heringer: ISIJ Int., 46 (2006), 880.

6) S. Y. Cho, T. Okane and T. Umeda: Foundry Engineering, 71 (1999), 246.

7) K. Nakajima and S. Mizoguchi: Bulletin of the Institute for Advanced Materials Processing (SOZAIKEN IHO), Tohoku University, 56 (2000), 107.

8) S. Kobayashi: Trans. Iron Steel Inst. Jpn., 28 (1988), 535.

9) Ch.-A. Gandin: Acta Mater, 48 (2000), 2483.

10) Y. C. Lee, A. K. Dahle, D. H. StJohn and J. E. C. Hutt: Mater. Sci. Eng. A, 259 (1999), 43.

11) M. D. Peres, C. A. Siqueira and A. Garcia: J. Alloy. Comp., 381 (2004), 168.

12) J. A. Taylor, G. B. Schaffer and D. H. StJohn: Metall. Mater. Trans. A, 30 (1999), 1651

13) Ph. Thevoz, J. L. Desbiolles and M. Rappaz: Metall. Trans. A, 20 (1989), 311.

14) M. A. Martorano, C. Beckermann and Ch.-A. Gandin: Metall. Mater. Trans. A, 34 (2003), 1657.

15) J. E. C. Hutt, D. H. StJohn, L. Hogan and A. K. Dahle: Mater. Sci. Technol., 15 (1999), 495.

16) R. J. Feller and C. Beckermann: Metall. Mater. Trans. B, 28 (1997), 1165 .

17) P. Hoefs, W. Reif and W. Schneider: Giesserei, 81 (1994), 398.

18) B. S. Murty, S. A. Kori and M. Chakraborty: Int. Mater. Rev., 47 (2002), 3 .

19) S. A. Kori, B. S. Murty and M. Chakraborty: Mater. Sci. Eng. A, 283 (2000), 94

20) J. D. Hunt: Mater. Sci. Eng., 65 (1984), 75.

21) D. M. Stefanescu: Science and Engineering of Casting Solidification, Plenum Pub Corp, New York, (2002), 180. 